\title{
Yerel Kalkınma Üçgeninde Sakin Şehir Hareketi: Yalvaç Örneği
}

\author{
Cansu Can AKCA \\ Süleyman Demirel Üniversitesi \\ cansucanakca@gmail.com \\ ORCID ID: 0000-0002-4494-0892 \\ Zişan KORKMAZ ÖZCAN \\ Süleyman Demirel Üniversitesi \\ zisankorkmaz@sdu.edu.tr \\ ORCID ID: 0000-0002-5842-8638
}

\section{Attf Bilgisi}

Araştırma Makalesi

DOI

Geliş Tarihi: 31.03.2021

Revize Tarihi: 29.10 .2021

DOI: $\quad 10.31592 /$ aeusbed. 907227

Akca, C. C. ve Özcan, Z. K. (2021). Yerel kalkınma üçgeninde Sakin Şehir Hareketi: Yalvaç örneği. Ahi Evran Üniversitesi Sosyal Bilimler Enstitüsü Dergisi, 7(3), 956-972.

\section{ÖZ}

Metropol şehirleşme ile yaşamların karmaşık bir biçim almasına alternatif olan Sakin Şehir (Cittaslow) hareketi, sakin yaşamı, kültürel ve doğal mirası, yerel kimliğin ve yerel yemeklerin korunarak sürdürülebilir olması amacı ile kurulmuştur. Covid-19 süreci ile halk artık doğal yaşamı tercih etmekte, nüfusun daha az olduğu, kalabalık olmayan yerleşim yerlerine yönelmektedir. Bu standartlara uygun yerleşim alanlarından olan sakin şehirlere yönelik talepler nüfus oranını artırmakta, nüfusun yoğunluğu ile ortaya çıkan çeşitli problemleri aşmak için ise iş birliği hareketini zorunlu kılmaktadır. Araştırma Isparta'nın Yalvaç ilçesi sınırları içinde yaşayan yerel paydaşları kapsamaktadır. Yerel kalkınma modeli olan sakin şehir hareketinin kalkınmaya yönelik katkısını belirlemek amacı ile nitel yöntem kullanılarak araştırma verileri ortaya konulmuştur. $\mathrm{Bu}$ amaç doğrultusunda Yalvaç ilçesinde ikamet eden 15 katılımcı ile yarı yapılandırılmış görüşme gerçekleştirilmiştir. Katılımcılar amaçlı örnekleme göre belirlenerek özel sektör, kamu sektörü ve sivil toplum kuruluşu üyelerinden oluşmaktadır. Elde edilen veriler çözümlenirken, betimsel ve içerik analizlerinden faydalanılmıştır. Çalışmanın sonucunda, katılımcılar tarafından Yalvaç ilçesinin Sakin Şehir faaliyetlerinin yerel kalkınmaya etkisinin tam anlamıyla gerçekleştirilemediği tespit edilmiştir. Araştırma sonuçları yerel halkın sakin şehir konusunda bilgi eksikliğini, yerel paydaşların diğer kurum ve kuruluşlar ile iş birliğine yönelik bilgilendirilmesi gerektiğini ortaya koymaktadır. Ayrıca her türlü el işçiliği, geçmişten günümüze aktarılması gerekli kültür unsurlarının desteklenmesi gerektiği, Sakin Şehir Yalvaç’ın tanıtılması ve yatırımlardaki eksikliklerin giderilmesiyle kalkınmayı olumlu yönde etkileyeceği sonuçları ortaya çıkmıştır. Araştırmanın ortaya çıkan sonuçları itibariyle başta Sakin Şehir Yalvaç olmak üzere diğer Sakin Şehirlere de ilgili paydaşlar aracılığı ile yol göstereceği olacağı düşünülmektedir.

Anahtar Kelimeler: Yerel kalkınma, sakin şehir (cittaslow), iş birliği, Yalvaç.

\section{The Cittaslow Movement in the Local Development Triangle: Yalvaç Example}

The Cittaslow movement, which is an alternative to the complex form of life with metropolitan urbanization, was established with the aim of preserving its calm life, cultural and natural heritage, local identity and local food. With the Covid-19 process, public now prefer natural life and turn to non-crowded settlements with the less population. Demands for Cittaslow, which are residential areas that comply with these standards, increase the population ratio, and require a cooperation act to overcome the various problems that arise with the density of the population. The research involves local stakeholders living within the borders of Yalvaç district of Isparta. In order to determine the contribution of the Cittaslow movement, which is the local development model, to the development, the research data were presented by using a qualitative method. For this purpose, semi-structured interviews were conducted with 15 participants residing in Yalvaç district. Participants were determined according to purposeful sampling and consist of members of the private sector, public sector and non-governmental organizations. Descriptive and content analysis were used while analyzing the obtained data. As a result of the study, it was determined by the participants that the effect of the Cittaslow activities of Yalvaç district on local development could not be fully realized. The results of the research reveal the lack of knowledge of the local people about the calm city and the need to inform the local stakeholders about cooperation with other institutions and organizations. In addition, it has been emerged that all kinds of handicrafts, the need to support cultural elements that need to be transferred from the past to the present, and the introduction of the Cittaslow Yalvaç and the elimination of the deficiencies in the investments will affect the development positively. Based on the results of the research, it is thought that it will guide other Cittaslow cities, especially Yalvaç, through the relevant stakeholders.

Keywords: Local development, cittaslow, governance, Yalvaç. 


\section{Giriş}

Dünyada birçok yerleşme ve şehirde küresellik etkeni açısından ciddi değişimler yaşanmaktadır. Bu değiş̧imler sosyo-psikolojik veya ekonomik olsa da, mimariden, alt yapıya çeşitli hizmetlerde bu değişimlere rastlamak mümkündür. Küreselleşmenin verdiği endişeler, yerellik ile küresellik konularının birlikte nasıl devam edebileceği üzerinedir. Özellikle, bir yere aitlik ve özgün niteliklerin sürdürülmesini hedefleyen şehirleşme hareketini ortaya çıkarmıştır. Bu hareketin önemli bir kısmını yerel kalkınma modelleri ile bir yere özgü gelişme hamleleri oluşturmaktadır. Yerel gelişmelere yönelik oluşturulan politikalar bölgeden bölgeye değiştiği gibi ülkeden ülkeye de değişebilen, birden fazla faktör ile etkileşim gerektiren bir süreçtir (Özür, 2016). Zira sakin hareketi kültürel anlamda değişimlerin de önüne geçmeyi hedeflemekte, insanların yaşam alanlarını daha iyi şekle getirerek, sakin bir yaşam şeklinin oluşmasını sağlamaya çalışmaktadır. Sakin şehir adına yapılacak olan yaşam alanlarına yönelik iyileştirmeler ile ekonomik, sosyo-kültürel anlamda katkılar elde edilebilmektedir. Kaliteli hizmet anlayışının sunulması ve iyileştirme politikaları ile kalkınma, yerel, bölgesel ve ulusal anlamda sağlanmış olacaktır.

Cittaslow tüzüğünde hareketin adı, Cittaslow-Yaşam kalitesine önem verilen şehirlerin uluslararası ağı olarak tanımlanmakta, "Cittaslow- Rete Internazionale delle città del buon vivere" şeklinde yer almaktadır (Cittaslow International Network, 2020). Türkçe karşıllı̆̆ Sakin Şehir olan Cittaslow, İtalyanca dil kökenine aittir. Cittaslow kelime kökeni "Citta" şehir ve İngilizce "Slow" olarak yani sakin ve şehir kelimelerinin birleşimi olarak Türkçe'ye "Sakin Şehir" veya "Yavaş Şehir" olarak çevrilmiştir (Seferihisar Belediyesi, 2018). Literatür incelendiğinde Cittaslow araştırmalarında yavaş şehir ismiyle kullanıldığı görülmektedir. Ancak anlam olarak "Yavaş" kelimesi tezatlık oluşturduğu için "Sakin" kelimesinin kullanımının daha uygun olduğu düşünülmektedir (Çolak, 2019; Ekinci, 2014). Uluslararası alanda "Slow City" olarak yaygın şekilde kullanılmakta olan Sakin şehir kavramı (Farelnik and Stanowicka, 2016), bir hareket olarak 15 Ekim 1999 yılında İtalya'nın Orvieto kentinde Paolo Saturnini tarafından kurulmuştur (Mayer ve Knox, 2010). Bu kapsamda sakin yemek hareketinin kurucusu Carlo Petrini ile Paolo Saturnini tarafindan sakin yemek hareketinin ilkelerinin kentsel yaşama uyarlanmasıyla hareketin temel prensipleri oluşturulmuştur (Pink, 2009). Orvieto'daki kuruluş toplantısında daha az kirli ve daha sakin fiziksel ortamlar için çalışmayı, yerel estetik gelenekleri ile yerel el sanatlarını korumayı, üretim ve mutfağı teşvik etmeyi içeren bir dizi ilke yer almaktaydı. Ayrıca, daha sağlıklı ortamlar yaratmak, vatandaşlara daha yavaş ve daha iyi yaşam için idari çözümler aramak, deneyimlerini paylaşmak için teknolojiyi kullanmak, iyi yemek, sağlıklı ortam, ekonomide sürdürülebilirlik ve geleneksel ritimlere dayalı yerlerin gelişismini teşvik etmek gibi amaçlar oluşturulmuştur (Knox, 2005).

Hareket başlangıçta sadece İtalya'daki belli başlı şehirleri kapsamaktayken, gelişen süreç kapsamında dünya çapında yayılarak uluslararası bir boyutta önem kazanmıştır. Sakin Şehir hareketi adının aksine, dünyada hızlı bir yayılma ve gelişim göstermektedir (Tunçer ve Olgun, 2017). Sakin Şehir hareketinin logosu, kabuğunun üzerinde şehir taşıyan turuncu renkli bir salyangozdur. Salyangoz sakinliği, ağırlığı ve kalıcılığı temsil etmektedir (Özür, 2016). Kabuğun üzerindeki şehir modern ve tarihi binaları sembolize ederken, bina sembolleri geçmiş ve şimdiki zaman arasında hılı ilerleme karşıtlığını ortaya koymaktadır (Alagöz, 2018). Sakin Şehir üyesi kentler bu logoyu üye olduklarına ve yavaşlanılması gerektiğine vurgu yapmak için kullanabilmektedir (Aydın ve Karakayacı, 2021).

Sakin Şehir kavramına yönelik literatür taraması sonucunda birçok tanıma raslanmaktadır. Sakin Şehir kavramı, küreselleşmeyle beraber yaşam tarzında ve şehir kavramında oluşan değişimleri en aza indirmeyi amaçlayarak yerel değerleri korumayı ilke edinen uluslararası bir birlik olarak tanımlanmaktadır (Şahin ve Kutlu, 2014; Tosun, 2013). Sakin Şehir kavramın başka bir tanımı ise bugüne ve geçmişe yansıyan yaşam tarzlarını iyileştirmek (Tunçer ve Olgun, 2017) için mevcut trendlere alternatif getirerek daha iyi gelecek bulmak ve yaşanılabilirliği savunmak şeklinde yapılmaktadır. Sakin şehirler bunları yaparken yerel değerleri ve doğal güzellikleri de korumaktadır (Ball, 2015; Jang ve Jung, 2015; Miele, 2008). Zira dünyadaki Sakin Şehir hareketi, uluslararas1 boyuta taşınarak yerel ayrıcalıklara vurgu yapmakta ve yerel yaşam kalitesini arttırarak iyileştirmeyi hedeflemektedir (Pink, 2008). Hareket, dünyanın çok farklı yerleşkelerinde Sakin Şehir hareketini 
uygulayan ve savunan uluslararası bir yaklaşım olma niteliği kazanmıştır. Hızlı küreselleşmeyi yönetebilmek amacıyla Sakin Şehir hareketi farklı kültürlerdeki şehirlerin kültürel mirasının korunmasında yol gösterici bir model olarak karşımıza çıkmaktadır (Bilgi, 2013; Çakar, 2016).

Hareket Avrupa kıtasından hızla yayılmaya başlamıştır. Zira günümüzde hemen hemen her ülkede Sakin Şehir hareketi üyesi şehir bulunmaktadır (Özür, 2016). İtalya'da başlayan Sakin Şehir Hareketinin, 2020 y1lı itibariyle dünyada 30 ülkede toplam 268 tane üyesi bulunmaktadır (Cittaslow, 2020). İtalya'nın bir kasabası olan "Greve in Chianti”, dünyada ilk Sakin Şehir olma niteliğine sahiptir (Kocaman ve Kocaman, 2019). Türkiye'de ise Sakin Şehir hareketinin başlamasında öncü yer Seferihisar ilçesi olmuştur (Yalçın, Yalçın ve Alıcı, 2018). Seferihisar belediye başkanı Tunç Soyer 2009 yılı Haziran ayında üyeliğe başvurarak, Seferihisar'ı tanıtmasıyla Ekim 2009'da Sakin Şehir üyeliğini elde etmiştir (Sezgin ve Ünüvar, 2011; Yalçın vd., 2018). Gelinen süreç kapsamında Sakin Şehir hareketinin önemi Türkiye'de her geçen gün hızla artmaktadır (Baykal ve Ataberk, 2020). Türkiye'de 2020 yılı itibariyle toplamda 18 Sakin Şehir üyesi kent bulunmaktadır (Cittaslow Türkiye, 2020). Bu şehirler Türkiye'nin hemen her bölgesinde bulunmakta olup, Seferihisar (İzmir), Akyaka (Muğla), Köyceğiz (Muğla), Gökçeada (Çanakkale), Şavşat (Artvin), Yalvaç (Isparta), Uzundere (Erzurum), Taraklı (Sakarya), Yenipazar 60 (Aydın), Göynük (Bolu), Perşembe (Ordu), Vize (Kırklareli), Halfeti (Şanlıurfa), Gerze (Sinop), Ahlat (Bitlis), Mudurnu (Bolu), Eğirdir (Isparta) ve Güdül (Ankara) şeklindedir.

Sakin Şehirler, yöre halkına yönelik sosyo- kültürel veya ekonomik anlamda katkı sağladığı bir yerel kalkınma örneği olarak çıkmaktadır. Asıl amacı kâr elde etmek olmayan Sakin Şehir hareketi yerel halkın kalkınmasında sosyo-ekonomik açıdan bunu en iyi şekilde ortaya koymaktadır. Zira sürdürülebilirlik kapsamında oluşturulmuş olan Sakin Şehir kriterleri şehirlerin gelişip korunmasına katkı sağlayarak pazar payını arttırmakta, halkın kalkınmasına yönelik oranlarda artış sağlamaktadır (Perano, Abbate, La Rocca ve Casali, 2019). Bu bakımdan Uluslararası Cittaslow Birliği'nin kuruluşu ile 59 adet olan kriter listesi, 2013'de Uluslararas1 Bilim Komitesi tarafından güncellenerek, 7 ana başlık halinde 72 kritere çıkarılmıştır. Sakin Şehir hareketinin ana politikaları ise sırasıyla çevre politikaları, altyapı politikaları, kentsel yaşam kalitesi politikaları, tarımsal, turistik, esnaf ve sanatkara yönelik politikalar, misafirperverlik, farkındalık ve eğitim için politikalar, sosyal uyum politikası ve ortaklıklar politikası şeklinde sınıflandırılmıştır (Cittaslow Türkiye, 2018; Mayer ve Knox, 2010; Sezgin ve Ünüvar, 2011). Bu politikalar çerçevesinde oluşturulmuş Sakin Şehir logosu bir kalite göstergesi olarak görülmektedir. Aynı şekilde Sakin Şehir anlamında sahip olunması gerekli kriterler, şehre gelen ziyaretçilerin ve bölge halkının yaşam kalitesinin artırılmasına yönelik kaliteyi ortaya koymaktadır (Sırım, 2012). Ancak bunu tek bir kurum ya da kuruluşun gerçekleştirmesi çok da mümkün değildir. Zira yerel yönetimlerin hedeflerine baktığımızda birçok görev listesi mevcuttur ve bunu tek başına başarmaları mümkün değildir. Bu çerçevede merkezi yönetimin, çeşitli kurum ve kuruluşların, sivil toplum kuruluşları ile Valilik ve diğer belediyelerin uluslararası birlikler ile çalışmaları gerekmektedir (Akman, Akman ve Karakuş, 2018). Kalkınma anlayışı açısından uygulanacak politikaların etkin şekilde hayata geçirilebilmesinde hedeflerin ve elde edilen sonuçların tüm sosyal aktörler tarafından katılımın gerçekleştirilerek, ayrıntılı görüşülmesini ve paylaşılmasını gerekli kılmaktadır. Böylece tüm aktörler iş birliği halinde sorunlara çözümler üretebilecek, kamu, özel sektör ve sivil toplum kuruluşları gibi tüm kesimlerin sahiplenmesiyle hem ekonomik hem de sosyal gelişme hızlanacaktır (Küçük ve Güneş, 2013). Ayrıca ülke genelini ilgilendiren bir kalkınma anlayışı ile bireylerin hayat standartları artmış, refah düzeyi yükselmiş bir toplumda yaşama imkânı artmış olacaktır. Turizmin gelişmesine yönelik katkı sağlayan hareket aynı zamanda uluslararası tanınırlığ olacaktır.

Dünyada önemli bir küresel değere sahip olan Cittaslow (Sakin Şehir) Uluslararası Birliği, Türkiye açısından 2020 yılı itibari ile 18 tane olan Sakin Şehir'in önemini korumakta ve arttırmaktadır. Isparta ili iki tane Sakin Şehre ev sahipliği yapmakta olup, ilk Sakin Şehir üyesi olan ilçesi Yalvaç, ikincisi ise Eğirdir'dir. Bu çalışma Sakin Şehir hizmetlerinin yerel kalkınmaya etkisinin, yerel paydaşlar üzerinden incelenmesi amaciyla yapılmıştır. Türkiye'de Sakin Şehir (Cittaslow) kavramının gelişmesine ve ilgili alanda yapılacak olan çalışmalara öncü olması ve yazılı kaynak 
olarak ele alınması beklenmektedir. Ayrıca Türkiye'nin 2012 yılında 8. Sakin Şehri olan Yalvaç'ın sürdürülebilir turizm kapsamında geliştirilmesine destek sağlanması amaçlanmıştır. Araştırmaya Yalvaç ilçesinin dahil edilmesinin önemi ise 2012 yllında Sakin Şehir üyeliğine kabul edilmesinden bugüne gelinen süre zarfinda, yerel kalkınmaya etkisinin azımsanmayacak derecede olmasıdır. Çalışmaya ilgili alanda literatür taraması ile başlanılmıştır. Bu anlamda daha önce yapılmış tez, bildiri, makale ve kitap ile ilgili yerli ve yabancı kaynaklar incelenmiştir. Bu kapsamında Yalvaç Belediyesi arşivinden ve faaliyet raporlarından yararlanılmış olup, yerel halk içerisinden kamu sektörü, özel sektör, sivil toplum kuruluşu gibi çeşitli gruplardan faydalanılmıştır. Çalışmanın tamamlanması amacıyla belirtilen gruplardaki kişilere çeşitli sorular yöneltilerek alınan cevaplar doğrultusunda sonuçlara ulaşılmaya çalışılmıştır. Bu çalışmada Sakin Şehir hizmetlerinin sürdürülebilir turizm çerçevesinde Yalvaç ilçesindeki yerel kalkınmaya etkisinin olumlu yönde olacağı düşüncesi ile araştırma konusu belirlenmiştir. Yalvaç, 2012 yılında uluslararası Sakin Şehir birliğine üye olmuştur. Üye olunan süreçten bugüne gelinen süre kapsamında ilçenin bilgi birikimi ve faaliyet alanlarındaki yoğunluğu dikkat çekmektedir. Bu bilgi birikiminin tam manası ile elde edilebilmesi için araştırmada, nitel yöntem aracılığı ile veri toplama sürecine gidilmiştir. Araştırma bölge sakinleri üzerinden gerçekleştirilmiştir. Araştırmanın biricik olması ve bölgeye katacağ1 yarar göz önünde bulundurularak alanyazına katkı sağlayacağı düşünülmekte ve çalışma kapsamında kamu özel sektör ve sivil toplum kuruluşlarına yöneltilen şu sorulara cevaplar aranmaktadır:

1. Sakin Şehir Olarak Planlar ve Turizme Yönelik Amaçlar hangi kesimde daha yoğundur?

2. Yalvaç'ın Sakin Şehir Olarak Avantajları ve Sakin Şehir Birliğinin Yerel Kalkınma Faaliyetleri nasıl gerçekleşmektedir?

3. Yalvaç'ın Sakin Şehir Kriterleri ve Yerel Halkın Faaliyetleri nelerdir?

\section{Yöntem}

Araştırmanın nasıl bir yöntemle desenlendiğinin gösterildiği bu kısımda, araştırmanın çalışma grubu, veri toplama araçları ve toplanan verilerin hangi yöntemlerle analiz edildiğine dair bilgilere yer verilmiștir.

\section{Araştırma Modeli}

Nitel araştırma, bilimsel araştırmalar kapsamında bir tür veri toplama yaklaşımı olarak tanımlanmaktadır (Bayyurt ve Seggie, 2017). Nitel araştırmalar, sosyal bilimler alanında insan davranışlarını ölçen, davranışların sebeplerini ve sosyal olayları derinlemesine analiz eden, sosyal bilim alanında yaygın olarak kullanılan araştırma yöntemlerinden biridir (Baltacı, 2019; Güler, Halıcıoğlu ve Taşğın, 2015). Bilimsel veriler gözlem, görüşme ve doküman analizi gibi nitel araştırma yöntemleri ile toplanabilmektedir (Bal, 2013; Yıldırım ve Şimşek, 2016). Nitel araştırma yöntemlerinden biri olan görüşme diğer tekniklere göre daha sık kullanılmaktadır. Görüşme tekniği incelenen literatür taraması sonucu karşımıza "mülakat" tekniği ismi kullanılarak çıkabilmektedir (Gürbüz ve Şahin, 2017). Görüşme teknikleri üç başlık altında toplanmaktadır. Bunlar yapılandırılmış görüşme, yarı yapılandırılmış görüşme ve yapılandırılmamış görüşme teknikleri olarak sınıflandırılmaktadır (Bal, 2013; Kuş, 2009). Yapılandırılmış görüşme, görüşme öncesi soruların belli olduğu ve belirli bir sıra doğrultusunda çalışma grubuna soruların yöneltilmesidir. Yapılandırılmış görüşmede soru kapsamının dışına çıkılamamaktadır. Yarı yapılandırılmış görüşme, soruların sayısı ve yeri çalışma grubuna göre esneklik göstermektedir. Soru kapsamının dışına çıkılabilmektedir. Yapılandırılmamış görüşme, soru sayısı ve sırası belli olmayıp çalışma grubuna göre değişebilmektedir. Çalışma gruplarına göre sorular görüşme sırasında spontane bir biçimde yöneltilmektedir (Güler vd., 2015; Kozak, 2018). Bu çalışmada, nitel araştırma yöntemi olan yarı yapılandırılmış görüşme tekniği ile veriler elde edilmiştir. Zira ulaşılmak istenilen çalışma grubu sınırlı sayıda kişilerden oluştuğu ve her bir çalışma grubundan farklı bilgiler elde edileceği düşünülerek yarı yapılandırılmış görüşme formu tercih edilmiştir.

Nitel araştırmaların geçerliliği ve güvenirliliği belli ölçütler doğrultusunda sağlanabilmektedir. Başlıca ölçütler araştırmanın nerede, kiminle, kaç kişiyle, kaç soruyla ve ne zaman yapıldığına 
ilişkindir (Kozak, 2018). Nitel araştırmaların ön geçerliliği amaçlanan sorunu ölçüyor nitelikte olmasıdır. İkinci aşama içerik geçerliliği, araştırma sorunsalı kavramını kapsıyor nitelikte olmasıdır. Üçüncü aşama kriter geçerliliği, elde edilen verilerden oluşmaktadır. Dördüncü son aşama dış geçerlilik, evreni temsil etme yetisine sahip örneklemi kapsamaktadır (Güler vd., 2015; Yıldırım ve Şimşek, 2016). Nitel araştırmaların güvenirliliği, araştırmacının verileri nesnel bir biçimde toplaması, benzer çalışmalar ile tutarlı olması ve sonuçların tutarlı olması ile ilgili deliller sunularak sağlanabilmektedir (Yıldırım ve Şimşek, 2016).

Çalışmanın temel yaklaşımı tümevarım yaklaşımıdır. Tümevarım yaklaşımı, araştırma sorunsalına yönelik alınan cevaplardan özelden genele doğru yol izlenmesi ve araştırmacının sorgulaması ile ilişkilendirilmektedir (Gürbüz ve Şahin, 2017; Kozak, 2018). Çalışmanın hedef kitlesine ulaş1lırken parçalardan bir havuz oluşturulmuştur. Çalışmada her katılımcıdan alınacak farklı bilgi parçacıklarından bir bütün oluş̧urularak tümevarılması amaçlanmıştır.

\section{Çalışma Grubu}

Araştırma evreni, bilimsel araştırmalarda araştırmacının gerçekte ilgilendiği ve öğrenmek istediği çalışma gruplarını, toplulukları, olayları vd. kitleri işaret etmektedir (Güler vd., 2015). Ancak araştırma sürecinde evrene ulaşmak güç ve maliyetli olabileceği için çoğunlukla örneklem seçilmektedir. Örneklem, evreni temsil edeceği düşünülen, evren içinden seçilen küçük kümeler olarak tanımlamak mümkündür (Aziz, 2014; Berg ve Lune, 2015). Bu çalışmanın evreni Türkiye'de mevcudiyet gösteren Cittaslow (Sakin Şehir) Birliğine üyeleri; örneklemi ise Isparta'nın Yalvaç ilçesi oluşturmaktadır. Çalışma grubu görüşme yöntemi ile araştırma sorunsalına en uygun cevap verebilecek kişilerden oluşturulmaktadır (Gürbüz ve Şahin, 2017). Bu kapsamda 15 katılımcı ile yüz yüze görüşülmüştür. Görüşme sorularına katılımcıların verdiği yanıtlar yinelenmeye başladığı ve doyum noktasına (Yıldırım ve Şimşek, 2013) ulaşıldığı için 15 katılımcıyla sonlandırılmıştır. Katılımcılar özel sektör, kamu sektörü ve sivil toplum kuruluşu üyesi olma şartı ile çalışmaya dahil edilmişlerdir. Araştırma sorunsalına uygun olarak seçilen kişilere ulaşılarak araştırma kapsamı netlik kazanmıştır. Katılımcılar olasılığa dayalı olmayan örnekleme tekniklerinden amaçlı örnekleme yöntemi ile belirlenmiştir (Yıldırım ve Şimşek, 2016). Amaçlı örnekleme, araştırmacının araştırma konusuna uygun olarak ulaşmayı belirlediği katılımcı gruplarını ifade etmektedir.

Nitel araştırmalar zamana, mekâna, kişiye, olaya ve duruma göre farkl1l1k göstermeleriyle dinamik bir yapıya sahiptir. Araştırma, araştırma sorunsalı ile sınırlı olduğu için genelleme yapmak mümkün olmamaktadır. Nitel araştırmalar nicel araştırmalara göre çalışma grubu sınırlı olduğu için evreni yansıtması güçtür. Çünkü nitel araştırma örneklemi özeldir ve toplum ile kısıtlanması mümkün değildir. Bundan dolayı çalışmaların sınırlılıkların belirlenmesi çalışmanın çevresini oluşturmada yardımcı olacaktır (Baltacı, 2019). Araştırmanın sınırlılıklarına aşağıda yer verilmiştir.

- $\quad$ Araştırma örneklemi, Cittaslow üyesi Yalvaç ile sınırlandırılmıştır.

- $\quad$ Araştırma, Yalvaç ilçesinde ikamet eden kamu çalışanı, özel sektör çalışanı ve sivil toplum kuruluşu çalışma grupları ile sınırlandırılmıştır.

- $\quad$ Araştırma, yarı yapılandırılmış görüşme tekniği ve katılımcıların vermiş oldukları cevaplar ile sınırlandırılmıştır.

- $\quad$ Araştırma, altı kamu sektörü, altı özel sektör, üç sivil toplum kuruluşu ile toplamda 15 katılımcı ile sınırlandırılmıştır.

- Araştırma, katılımcıların belli bir zaman dilimi içerisindeki görüşleri ile sinırlandırılmıştır.

- Araştırma, yarı yapılandırılmış görüşmeler neticesinde elde edilen veriler ile sınırlandırılmıştır. 


\section{Veri Toplama Araçları}

Araştırma verileri, katılımcılar ile yüz yüze görüşülerek elde edilmiştir. Elde edilen veriler ses kayıt cihazına kaydedildikten sonra yazılı döküme işlenmiştir. Araştırma öncesinde literatür taraması yapılarak, çalışma kapsamında var olan alan yazın eksiklikleri belirlenmiştir. Ardından katılımcılara sorulacak olan ve sekiz sorudan oluşan Yarı Yapılandırılmış Görüşme Formu oluşturulmuştur. Görüşülecek çalışma grubu önceden belirlenmiş olup görüşmeler telefonla randevu talep edilerek ve doğrudan görüşme yöntemiyle gerçekleştirilmiştir. Kaymakamlık ile görüşme talep edilmiş ancak talep doğrultusunda görüşme gerçekleştirilemediği için çalışmanın nitel kısmına dahil edilememiştir. Randevular günün farklı saatlerinde planlanmış ve görüşmeler katılımcıların çalıştı̆ı kurum ve kuruluşlarda gerçekleştirilmiştir.

\section{Verilerin Toplanması ve Analizi}

Veri toplama sürecinde her bir katılımcı ile ortalama 15 dakika süren görüşmeler gerçekleştirilmiştir. Toplam 230 dakikayı bulan görüşmeler, katılımcıların izni doğrultusunda ses kayıt cihazı ile kayıt altına alınmıştır. Ses kayıtları görüşme günü veya en geç görüşmeden sonraki gün yazılı döküme dönüştürülmüştür. Toplam görüşme kayıtları 17 Word sayfasından oluşmaktadır. Görüşme sırasında bir katılımcı ses kayıt cihazına izin vermemiştir. Elde edilen veriler öncelikle ham haldeyken özetlenmeli, gereksiz veriler temizlenmeli ve işlenmelidir. İşlenen veriler araştırma sorunsalını ortaya çıkarmalıdır (Gürbüz ve Şahin, 2017). Bu yüzden görüşmeler esnasında gerekli görüldüğü zaman sorulan soruların alternatif soruları katılımcılara yöneltmiş ve önemli görülen cevaplar not edilmiştir.

\section{Araştırma Etiği}

Süleyman Demirel Üniversitesi Sosyal ve Beşeri Bilimler Etik Kurulu (24/02/2021 tarih ve E87432956-050.99-24426 sayı) tarafindan bilimsel çalışmanın kapsam ve uygulama açısından etik ilkelere ve insan haklarına uygun olduğuna karar verilmiştir.

\section{Bulgular}

$\mathrm{Bu}$ bölümde araştırmaya katılan katılımcıların Sakin Şehir kavramı ve yerel kalkınma kavramına ilişkin bütünleştirici sorulara verilen yanıtlara yer verilmektedir. Katılımcılara yöneltilen sorulara verilen yanıtlara göre üç tema başlığı altında toplanmıştır. Her bir temaya verilen cevaplar kamu sektörü, özel sektör ve sivil toplum kuruluşu (STK) çalışanlarının vermiş oldukları yanıtlara göre ayrıştırılmıştır.

Araştırmada görüşmelerin gerçekleştirildiği yerel paydaşların cinsiyetleri, çalışma alanları aşağıdaki tabloda sunulmuştur.

Tablo 1

Görüşme Sağlanan Katılımcılar, Cinsiyeti, Çalışma Alanı

\begin{tabular}{lll}
\hline Paydaş & Cinsiyet & Çalş̧ma Alanı \\
\hline P1 & Erkek & Kamu Sektörü \\
P2 & Erkek & Kamu Sektörü \\
P3 & Erkek & Kamu Sektörü \\
P4 & Erkek & Kamu Sektörü \\
P5 & Erkek & Kamu Sektörü \\
P6 & Erkek & Kamu Sektörü \\
P7 & Kadın & Özel Sektör
\end{tabular}




$\begin{array}{lll}\text { P8 } & \text { Erkek } & \text { Özel Sektör } \\ \text { P9 } & \text { Erkek } & \text { Özel Sektör } \\ \text { P10 } & \text { Kadın } & \text { Özel Sektör } \\ \text { P11 } & \text { Kadın } & \text { Özel Sektör } \\ \text { P12 } & \text { Kadın } & \text { Özel Sektör } \\ \text { P13 } & \text { Erkek } & \text { STK } \\ \text { P14 } & \text { Erkek } & \text { STK } \\ \text { P15 } & \text { Erkek } & \text { STK }\end{array}$

Tablo 1'de yer alan P1, P2,.., P15 şeklinde kodlanan toplamda 15 katılımc1 ile yapılan görüşmeden, 6 katılımcı kamu sektörü çalışanı, 6 katılımcı özel sektör çalışanı ve 3 katılımcı STK üyesinden oluşmaktadır. Katılımcıların \%40 kamu çalışan1, \%40 özel sektör çalışanı ve \%20 STK üyesinden oluşmaktadır. Katılımcıların 11'i erkek, 4'ü kadın çalışma grubundan oluşmaktadır. Katılımcıların \%73,3 erkek çalışma grubundan oluşmaktadır.

\section{Sakin Şehir Olarak Planlar ve Turizme Yönelik Amaçlar}

$\mathrm{Bu}$ başlık altında Yalvaç ilçesinin Sakin Şehir kapsamında sürdürülebilir yerel kalkınma kıstasına göre üç farklı soru üzerinden değerlendirmesi yapılmıştır. Değerlendirmeler kamu sektörü, özel sektör ve sivil toplum kuruluşları üzerinden ayrı başlıklar altında değerlendirmeye tabi tutulmuştur. Görüşmeler dahilinde Yalvaç’ın Sakin Şehir olarak planları ve turizme yönelik amaçları genel olarak değerlendirilmiştir. Katılımcılara aşağıdaki sorular yöneltilmiştir:

- Sakin Şehir olduktan sonra hedeflerinize ulaşabildiniz mi? Süreci değerlendiriniz.

- Sakin Şehir olarak neleri ön planda tutuyorsunuz?

- Sakin Şehir olarak turizme yönelik amaçlarını?

Sorularına verilen cevaplar katılımcı gruplarına göre ayrı başlıklar altında yer verilmiştir.

\section{Kamu Sektörü ile Yapılan Görüşmelerin Değerlendirilmesi}

Kamu sektörü katılımcılarına, Sakin Şehir sürecini değerlendirme ve hedeflerine yönelik soru yöneltilmiştir. Katılımcılar tarafından Sakin Şehir Birliğinin küreselleşmenin getirilerinden kaçabilmek için firsat sağladığı, ancak bilinçlendirmede eksikler olduğu için çalışmaların yetersiz kaldığı söylenilmektedir. Yalvaç'ın 2012 yılında Sakin Şehir Birliğine üye olduğu ancak gelinen süre kapsamında hiçbir ilerleme görülmediği belirtilmiştir. Faaliyetlerin kâğıt üzerinde kaldığı ve Sakin Şehir olarak hedeflerin ise gerçekleştirilemediği söylenilmektedir. Bu doğrultuda öncelikle halkın bilinçlendirilmesi ve eğitimli bireylerin artması için çalışmaların yapılması gerektiği, Sakin Şehir olarak Yalvaç'ın reklam ve tanıtım çalışmalarının ön planda tutulması gerektiği söylenilmektedir. Belediye'nin ise yenilebilir güneş enerjisi kaynaklarının sağlanması, bisiklet yolu ve engellilere yönelik düzenlemeleri kapsayan altyapı çalışmalarının yapılması ve zanaatkarların devamlılı̆̆ının sağlanması kapsamında faaliyetlerin gerçekleştirilmesi gibi çalışmaları ön planda tuttuğu belirtilmektedir.

Yalvaç'ın Sakin Şehir olması ile kamu sektörünün ön planda tuttuğu çalışmalar aşağıdaki gibidir:

P1: "Yalvaç öncelikle tarihi yapısıyla ön plana çıkmaktadır. Sakin şehir olarak faaliyetlerimiz ise yerel el sanatlarının devamını sağlamak. Yalvaç'ta Keçecilik ve Dericiliğin çok önemli bir yeri vardır. Yine geleneksel yemeklerimizin satışı için belediyenin tamamen denetimini sağladı̆̆ bir tarihi konak restore edilmiş ve "Geleneksel Yemek Evine" çevrilerek yerel halktan kişilerce işletilmektedir. Kentimizde engellilere yönelikte çalışmalar yapılmaktadır, engelli bireylere 
yönelik toplu taşıma, asansör yapımı gibi faaliyetlerimiz vardır. Tarihi yapılarda restorasyon çalışmalarımızda bulunmaktadır.

P2: “Alt yapı çalışmaları, alternatif yenilenebilir güneş enerjisi, bisiklet yolu çalışmalarımız var hem kendi idealimiz hem de sakin şehir için önemli çalışmalar. Kentimize fastfood tarzl yemeği sokmuyoruz yerel yemeklerin satılması ve yenilmesi çabası içerisindeyiz."

Katılımcılara Sakin Şehir olarak Yalvaç'ın turizme yönelik amaçları sorusu yöneltildiğinde, Psidia Antik Kent'inin inanç turizmi kapsamında geliştirilmesi gerektiği belirtilmektedir. Psidia Antik Kent'inde yapılan kazı ve restore çalışmalarına hız verilmesi gerektiği söylenilmektedir. Katılımcıların Sakin Şehir olarak turizme yönelik amacının, kırsal turizm kapsamında faaliyet yürütmek olduğu belirtilmiştir. Kırsal turizm kapsamında, turistlerin konaklamalarını ve tarımsal faaliyette bulunmalarını hedefledikleri, bu amaç doğrultusunda eski Yalvaç evlerinin pansiyon olarak restore edilmesiyle turizm sektörüne kazandırılması gerektiği düşünülmektedir. İlçeye gelen ziyaretçiye hizmet verebilecek yeterli sayıda konaklama işletmesinin olmadığı ve bu doğrultuda bakanlık belgeli konaklama işletmesinin arttırılması gerektiği söylenmektedir. Ayrıca turizme yönelik PR (Piar) çalışmalarına önem verilmesi gerektiği belirtilmektedir.

\section{Özel Sektör ile Yapılan Görüşmelerin Değerlendirilmesi}

Özel sektör katılımcılarına, Sakin Şehir sürecini değerlendirme ve hedeflere yönelik soru yöneltildiğinde, ileriye dönük hedeflerinin olmadığı söylenmektedir. Özel sektör çalışanlarının, işletmelerinin reklam ve pazarlama gibi faaliyetlerini kendi imkanları doğrultusunda sağladıkları, kurum ve kuruluşların desteğini almadıkları söylenilmektedir. Katılımcıların, öncelikli olarak hizmeti ön planda tuttuğu, misafir/müșteri memnuniyetine önem verdikleri görülmektedir. Katılımcılara Sakin Şehir olarak Yalvaç'ın turizme yönelik amaçları sorusu yöneltildiğinde ise işletmelerin, turist çekebilmek ve müşteri pazarını oluşturmak için sosyal medyada tanıtım ve reklam çalışmalarını sürdürdüklerini söylenilmektedir. Ayrıca katılımcılar tarafından, ziyaretçilere yönelik çalışmalar yapmaktan ziyade kendi pazarına ve tüketicilerine yönelik faaliyetlerde bulundukları belirtilmektedir.

\section{STK ile Yapılan Görüşmelerin Değerlendirilmesi}

Sivil toplum kuruluşu katılımcılarına, Sakin Şehir sürecinin değerlendirilmesi ve hedefleriniz sorusu yöneltildiğinde, yaşam standartlarının yükseltilmesi, sağlıklı yiyeceklerin üretilmesi ve tüketilmesi doğrultusunda hedeflerinin olduğu söylenmiştir. Katılımcılar Sakin Şehir olarak süreci değerlendirdiğinde, idarecilerin Yalvaç'a Sakin Şehir olarak gerekli değeri ve önemi göstermedikleri belirtilmiştir. Yerel halkın, Sakin Şehir kavramının bilincini kazanmadığı düşünülmektedir.

Yalvaç'ın Sakin Şehir olmasının STK katılımcıları tarafindan turizme yönelik amaçları kapsamında düşünceleri aşağıdaki gibidir:

P14: "Sanat evi projesi tasarladlk ancak 3 ylldir izin alamadık. Sanat evinde semerci, keçeci, kalaydl, derici, halı dokumacı, ağaç oymacıllı̆̆l, resimci gibi birçok faaliyette bulunan işletmeleri oraya taşıyacaktık. Turist geldiği zaman tüm işletmeleri bir arada gezecekti. Bunun yanında misafirhanelerde yapacakttk çünkü Yalvaç merkezde bütün konaklama işletmeleri birbirinden farkl yerlerde turist böyle olunca gidemiyor o yerleri gezemiyor."

Katılımcılar tarafından turizme yönelik, "Sanat Sokağı Projesi" geliştirdikleri fakat destek bulamadıkları söylenilmiştir. Sanat sokağı projesinin kapsamı ise, etkinliklerin ve faaliyetlerin tek bir mahallede toplanılmasıdır. Sanat sokağı ile ziyaretçiler, ilçe merkezinde dağınık olarak bulanan işletmelere tek bir noktada erişmeleri ile zamandan ve enerjilerinden tasarruf etmeleri sağlanacağı belirtilmiştir. İşletmelerin kalkınmasına katkı sağlayacağı katılımcılar tarafından söylenilmiştir. Ancak projelerine destek çıkmadığı için askıda kaldığını belirtilmiştir. 


\section{Yalvaç'ın Sakin Şehir Olarak Avantajları ve Sakin Şehir Birliğinin Yerel Kalkınma Faaliyetleri}

Bu başlık altında Yalvaç ilçesinin Sakin Şehir kapsamında sürdürülebilir yerel kalkınma kıstasına göre iki farklı soru üzerinden değerlendirmesi yapılmıştır. Değerlendirmeler kamu sektörü, özel sektör ve sivil toplum kuruluşları üzerinden ayrı başlıklar altında değerlendirmeye tabi tutulmuştur. Görüşmeler dahilinde Yalvaç'ın Sakin Şehir olarak avantajları ve sürdürülebilir yerel kalkınmaya yönelik faaliyetleri genel olarak değerlendirilmiştir. Katılımcılara aşağıdaki sorular yöneltilmiştir:

- Sakin Şehir olarak avantajlarınız ve size kazandırdıkları nelerdir?

- Sakin Şehir olarak sürdürülebilir yerel kalkınma faaliyetlerinizden bahseder misiniz?

- Yerel kalkınmaya etkisi sizce neden önemlidir?

Sorularına verilen cevaplar katılımcı gruplarına göre ayrı başlıklar altında yer verilmiştir.

\section{Kamu Sektörü ile Yapılan Görüşmelerin Değerlendirilmesi}

Kamu sektörü katılımcılarına Sakin Şehir olarak avantajlarınız nelerdir sorusu yöneltildiğinde, katılımcılar Sakin Şehir (Cittaslow) birliğinin uluslararası bir organizasyon olmasından dolayı Yalvaç'ın uluslararası bir alanda tanılıyor olmasını Yalvaç için avantaj olduğunu düşünmektedir. Ancak katılımcılar, Yalvaç'a başka bir katkısı ve kazanımı olmadığını belirtmişlerdir. Katılımcılar tarafindan Sakin Şehir olarak Yalvaç'ın sadece ilçe merkezinin giriş yolunda bulunan Cittaslow tabelasından ibaret olduğu söylenmektedir.

Yalvaç'ın Sakin Şehir olmasının kamu sektörü katılımcıları tarafından yerel kalkınma faaliyetleri kapsamında düşünceleri aşağıdaki gibidir:

P4: "Yeni nesil hastalı̆̆ masa başı iş olduğu için inşallah en yakın zamanda yeni nesil kendi köyünde ya da kasabasinda çalışması gerekliliği milli eğitimde seferberlik çağrıslyla eğitilmesi gerekmektedir. Biz halkımıza sakin şehir olmayı anlatamadık ve sakin şehir kriterlerinde bir kent olduğumuzdan olağan dışı bir durum olmadığından halkımıza anlatamıyoruz."

P5: "Yerel kalkınma için öncelikle yerel işletmeler, halk ve idareciler bir araya gelmelidir. Çünkü birlik olarak hareket edilirse yerel kalkınma mümkün olur. Yalvaçta halk kendi kazancının peşinde kendi haline çallş̧an kişiler ama şu var burada önemli meslek dallarl var ve bitmeye yüz tuttu devamı yok yani bunlar derici, keçeci, semerci bunları devam ettirecek kalifiye eleman yok."

Katılımcılara Sakin Şehir olarak sürdürülebilir yerel kalkınma faaliyetleriniz sorusu yöneltildiğinde, katılımcılar yerel halkın ürettiği yerel ürünlerin satışının yapabildiği bir kadınlar pazarına sahip olduklarını belirtmiş̧tir. Halk firınlarında Yalvaç yöresine ait "Hamursuz", ekmek ve börek çeşitlerinin satışının yapıldığ yerel kalkınmayı olumlu etkilediği belirtilmiştir. Ayrıca katılımcılar yerel kalkınmada önemli gördükleri bir miras olan zanaatkarlı̆̆ın bitmeye yüz tuttuğunu, bu alanda çalışmaların olmadığı veya yetersiz olduğu söylenmektedir. Yalvaç'ın önemli zanaatları ise Dericilik, Keçecilik ve Semercilik şeklinde olup, faaliyetlerini hala sürdürmekte oldukları ancak gelecek kuşaklara aktarılması konusunda endişeli oldukları söylenilmektedir. $\mathrm{Bu}$ doğrultuda yerel kalkınma faaliyetlerini sürdürülebilir kılmak için kamu sektörü, özel sektör ve yerel işletmelerin bir araya getirilmesi ve birlikte hareket etmeleri halinde ancak o zaman yerel kalkınmaya katk1 sağlayacağ 1 katılımcılar tarafından söylenilmektedir.

\section{Özel Sektör ile Yapılan Görüşmelerin Değerlendirilmesi}

Özel sektör katılımcılarına Sakin Şehir olarak avantajlarınız sorusu yöneltildiğinde, katılımcılar tarafından kentin turizm amaçlı potansiyelinin yüksek olduğu, Sakin Şehir amaçlı gelen turistlerin ise bu değerin farkında olmadıkları ve bu kapsamda kurum ve kuruluşların faaliyetlerinin olmadığı söylenilmektedir. Ayrıca avantajları kapsamında, Yalvaç’ın kültürel ve tarihi değerlerinin ön 
planda olduğu ve bu değerlerin korunabildiği ender şehirlerden birisi olduğu söylenmektedir. Yalvaç'ın Sakin Şehir olarak dezavantajının ise şehir yerleşkesinin anayol güzergahının dışında kalması ve inanç turizmi için gelen turist kitlelerinin şehir merkezine uğramadan geri dönmeleri söylenebilir.

Yalvaç’ın Sakin Şehir olmasının avantajları sorusu yöneltildiğinde özel sektör katılımcısı tarafından olumsuz görüşü aşağıdaki gibi ifade edilmektedir:

P7: “Yalvaç'ın Sakin Şehir olduğunu bilen ve sirf sakin şehir olduğu için gezmeye gelen turist kitlesi var ama avantaj sağlamadı. Çünkü tanıtım eksiklikleri var. Sakin şehir olduğu iç̧in değgil ama antik kent için günlük yaklaşı 10 otobüs tur araçları geliyor ama bize bir etkisi yok tur otobüsleri bile şehir merkezine gelip durmuyor hatta konaklamıyorlar bile".

Katılımcılara Sakin Şehir olarak sürdürülebilir yerel kalkınma faaliyetlerinin neler olduğu sorusu yöneltildiğinde, katılımcılar kendi imkanları dahilinde işletmelerinin reklam, pazarlama ve tanıtım çalışmalarını yürüttükleri söylenmiştir. İşletmeler açısından Yalvaç'ın Sakin Şehir üyesi olmasının bir avantaj sağlamadığı belirtilmektedir. Katılımcılar tarafindan yerel kalkınmanın sadece belli dönemlerde turistlerin gelmesi ile sağlandığı ve kazançlarının o dönem çok iyi olduğu ancak sonrasında işlerin düştüğü belirtilerek bu doğrultuda kalkınmanın gerçekleşmediği söylenilmektedir. Yerel kalkınma kapsamında, önemli zanaatkarların bulunduğu, el sanatlarına verilen önem derecesi artarsa sürdürülebilir bir iş kolu olacağı ve ekonomik getirisinin yüksek olacağı söylenmektedir.

\section{STK ile Yapılan Görüşmelerin Değerlendirilmesi}

STK katılımcılarına, Sakin Şehir olmanın avantajları sorusu yöneltildiğinde, katılımcılar tarafından trafiğin az olması, huzur ortamı olması, güvenlik probleminin olmaması, sağlıklı yiyeceklerin olması ve yaşanılabilir olması söylenmiştir. Katılımcılar yerel kalkınma kapsamında, idarecilerin desteğinin olmadığını söylemiştir. Yalvaç'ın önemli iş kollarının Semercilik, Keçecilik ve Dericilik olduğu ancak işletme sahipleri ölünce devam ettirecek kalifiye elamanın olmadığ 1 ve sürdürülebilirlik kapsamında çalışmaların olmadığı katılımcılar tarafından söylenilmektedir.

\section{Yalvaç’ın Sakin Şehir Kriterleri ve Yerel Halkın Faaliyetleri}

Bu başlık altında Yalvaç ilçesinin Sakin Şehir kapsamında sürdürülebilir yerel kalkınma kıstasına göre üç farklı soru üzerinden değerlendirmesi yapılmıştır. Değerlendirmeler kamu sektörü, özel sektör ve sivil toplum kuruluşları üzerinden ayrı başlıklar altında değerlendirmeye tabi tutulmuştur. Görüşmeler dahilinde Yalvaç'ın sürdürülebilir bir Sakin Şehir olmasının kriterleri ve bu kriterler kapsamında yerel yemeklerin satışının gerçekleştirilmesi ve yerel halkın Sakin Şehir olarak ne derece faaliyet gösterdiğine yönelik soruların cevapları genel olarak değerlendirilmiştir. Katılımcılara aşağıdaki sorular yöneltilmiştir.

- Sürdürülebilir bir Sakin Şehir olmanın kriterleri sizce nelerdir?

- Sakin Şehir anlamında yerel halk ne derece faaliyet yürütüyor?

- $\quad$ Sakin Şehir kriteri olan, Yerel yemeklerin satışı yapılıyor mu?

Sorularına verilen cevaplar katılımcı gruplarına göre ayrı başlıklar altında yer verilmiştir.

\section{Kamu Sektörü ile Yapılan Görüşmelerin Değerlendirilmesi}

Kamu sektörü katılımcılarına sürdürülebilir Sakin Şehir olmanın kriterleri sorusu yöneltildiğinde, katılımcılar tarafından yerel halkın bilgilendirilme ve bilinçlenmesine yönelik toplantıların yapılması, sağlıklı yiyeceklerin sürdürülebilir kılınması, yaşam standartlarının yükseltilmesi, yerel halk, belediye ve üniversitenin beraber çalışmalar yürütmesi, nüfus artışının ve göçün önüne geçilmesi gerektiği söylenilmektedir. Katılımcılar yerel halkın faaliyetlerinin Sakin Şehir kapsamında olmadığını söylemektedir. Bağımsız olarak faaliyette bulunduklarını fakat bunun da sürdürülebilir olmadığı söylenmektedir. Katılımcılar yerel yemekleri olan "Hamursuz" ürünün mahalle fırınlarında satışının yapıldığını söylemektedir. 


\section{Özel Sektör ile Yapılan Görüşmelerin Değerlendirilmesi}

Özel sektör katılımcılarına sürdürülebilir Sakin Şehir olmanın kriterleri sorusu yöneltildiğinde, katılımcılar tarafından doğal çevrenin korunması, yerel kalkınmada sürekliliği sağlayan iş kollarının bulunması, Sakin Şehir olarak yerel halkın bilinçlendirilmesi, trafik sorununun giderilmesi ve yerel paydaşların birlikte faaliyetler yürütmesi gerektiği söylenilmektedir. Katılımcılar, yerel halkın faaliyetlerinin kendi çalışma stratejisi ile yürüttükleri ve Sakin Şehir anlamında faaliyet göstermediklerini söylenmektedir. Bu hususta yerel yönetimlerin teşvik ve çalışmalar yürütmesi gerektiği belirtilmiştir. Katılımcılar, yörenin yemeklerin aktarılması ve tanıtımının yapılması amaçlı restoran olduğu ve mahalle firınlarında hamur işlerinin satışının yapıldığını söylemektedir.

Sakin Şehir kriteri olan, yerel yemeklerin satışının yapılması sorusu yöneltildiğinde özel sektör katılımcısı görüşünü aşağıdaki gibi ifade etmektedir:

P9: "Yöremize ait yemeklerin bulunduğu Nur Konakları adlı tesis son bir yıl içerisinde açıldı. Bir diğer yöremize ait yemeğimiz olan Hamursuz mahalle firınlarında sicak satısl yapıllyor. Ama benim canım keşkek çektiğinde gidip yiyeceğim bir yer yok maalesef. Nur Konakları bir gün öncesi verilen sipariş üzerine yerel yemekleri yapıyor."

\section{STK ile Yapılan Görüşmelerin Değerlendirilmesi}

STK katılımcılarına sürdürülebilir Sakin Şehir olmanın kriterleri nelerdir sorusu yöneltildiğinde, katılımcılar tarafından barış ve güven ortamının olması, aile ve komşu bağlarının güçlü olması, çevre bilincinin oluşması, araç trafiğinin olmaması, bisiklet kullanımının olması, bisiklet yollarının bulunması ve belediyenin bilgilendirme çalışmaları yapması gerektiği söylenilmektedir. Katılımcılar, yerel halkın faaliyetlerinin kendileriyle sınırlı olduğunu ve Sakin Şehir olmak Yalvaç'ın yerel kalkınmasına etki etmediğini belirtmektedir. Katılımcılar, yerel yemeklerinin kültürel miras olduğunu ve mahalle firınlarında satışının sürdürüldügünü belirtmektedir.

Sakin Şehir anlamında yerel halkın faaliyetleri sorusuna STK katılımcısı görüşünü aşağıdaki gibi ifade etmektedir:

P15: "Yerel işletmeler kendi çabalarlyla bir şeyler yapıyor. İşte minyatür araba yapan var, dericimiz var, keçecimiz var ama yerel yönetim bunlara gerekli değeri göstermiyor."

\section{Sonuç, Tartıșma ve Öneriler}

Toplumsal yaşantıların hızlı olması ana problemine karşın, Sakin Şehir birliği nefes almayı ve yavaşlamayı vaat etmektedir. Metropol şehirlerin bunaltan trafiğinden, gürültüsünden, kirliliğinden ve yoğunluğundan kaçarak, öz değerlerini koruyan yerel şehirlerde yaşamayı sunmaktadır. Özellikle son zamanlarda yaşanan Covid-19 süreci ile Sakin Şehirlerin aranan kriterlere cevap vermesi ilgi uyandırmaktadır.

Çalışma konusunun seçiminde, Sakin Şehir hizmetlerinin yerel kalkınmaya sağladığı desteği ölçmeye yönelik çalışmaların sınırlı sayıda olması ve literatür taramasındaki eksiklerin olduğunun görülmesi etkili olmuştur. Yalvaç, 2012 y1lında uluslararası Sakin Şehir birliğine üye olmuştur. Üye olunan süreçten bugüne gelinen süre kapsamında ilçenin bilgi birikimi ve faaliyet alanlarındaki yoğunluğu dikkat çekmektedir. Bu bilgi birikiminin tam manası ile elde edilebilmesi için araştırmada nitel yöntem aracılığı ile veri toplama sürecine gidilmiştir. Nitel araştırma kapsamında 15 katılımcı ile yüz yüze yarı yapılandırılmış görüşme yöntemi ile veriler toplanmıştır. Söz konusu katılımcılar amaçlı örneklem yöntemine göre seçilerek, bulguların homojen ve temsil edilebilir olabilmesi için kamu sektörü çalışanı, özel sektör çalışanı ve sivil toplum kuruluşu üyelerinden seçilmiştir. Elde edilen veriler bulgular başlığı adı altında üç alt başlıkta derlenmiştir. Üç başlıktan oluşan temalar, Sakin Şehir olarak planlar ve turizme yönelik amaçlar, Yalvaç'ın Sakin Şehir olmasının avantajları ve sakin şehir hizmetlerinin yerel kalkınma faaliyetleri, Yalvaç'ın Sakin Şehir kriterleri ve yerel halkın faaliyetleri 
olarak oluşturulmuştur. Her bir temanın bulguları kamu sektörü çalışanı, özel sektör çalışanı ve sivil toplum kuruluşu üyelerinden oluşan katılımcıların vermiş oldukları cevaplar doğrultusunda ayrı ayrı gruplandırılmıştır.

Bu çalışmada yerel paydaşlar, Sakin Şehir üyeliğinin uluslararası alanda Yalvaç'ın adının geçmesi ile tanınırlık seviyesinin artmasında avantaj sağladığ 1 görüşündedirler. Üyelik ile yaşam standartlarının yükseldiği, sağlıklı yiyeceklerin üretildiği ve tüketildiği, alt yap1 ve üst yap1 olanaklarının standardize olduğu, engelli bireyler için yaşamı kolaylaştırıcı faaliyetler yürütüldüğü ve temiz doğa için bisiklet yollarının yapılmasında katkı sağladığı sonucuna ulaşılmıştır. Yalvaç ilçesi kültürel ve tarihi değerleri ile ön plana çıkmaktadır. Gelen ziyaretçilerin büyük kısmının inanç turizmine yönelik gelmesi tarihi yerlerin hızla restore edilmesi gerektiği sonucunu karşımıza çıkarmaktadır.

Çalışmada yerel paydaşlar, Yalvaç'ın Sakin Şehir olması ve faaliyetleri doğrultusunda olumsuz yönde bazı değerlendirmelerde bulunmaktadır. $\mathrm{Bu}$ değerlendirmeler arasında yerel paydaşların birbirinden bağımsız olarak çalışmalar yürütmesinin yöre halkı için önemli bir problem olduğu sonucu yer almaktadır. Bu kapsamda Sakin Şehir faaliyetlerinin yalnızca kamu kurum ve kuruluşları tarafından değil, aynı zamanda yerel halk, özel sektör, STK ve üniversite kurumlarınca bilim komiteleri oluşturularak gerçekleşmesi gerektiği sonucuna ulaşılmaktadır. Bu hususta yerel paydaşların ortak hareket etmeleri gerekliliği ortaya konulmaktadır. Elde edilen bu sonuç Küçük ve Güneş (2013)'in yapmış oldukları çalışma bulguları ile benzerlik göstermektedir.

Yerel kalkınmanın önemli bir bacağını oluşturan turizm sektörü, Yalvaç ilçesinde inanç turizmi doğrultusunda turistlere hizmet ettiği bilinmektedir. Ancak turizm faaliyetleri doğrultusunda şehir merkezinde yeterli konaklama tesisinin bulunmadığı ve bu doğrultuda bakanlık belgeli konaklama tesislerinin arttırılmasına yönelik çalışmaların yapılması gerektiği sonucuna ulaşılmaktadır. Ayrıca çalışmada Yalvaç ilçesinde zanaatkara gerekli değerin verilmediği ve yok olma tehlikesi ile karşı karşıya kalındığı, yerel yönetimlerin destekleyici faaliyetlerinin eksik kaldığı sonucuna ulaşılmaktadır. Elde edilen bu sonuç Tunçsiper ve Yılmaz (2009)'ın yapmış oldukları araştırma sonuçları ile benzerlik göstermektedir.

Sakin Şehir birliği sürdürülebilir yerel kalkınma için model önerisi sunmaktadır. Ancak elde edilen bulgular neticesinde Yalvaç bölgesinde yerel kalkınmanın tam olarak desteklenmediği, Sakin Şehir adına yapılan çalışmaların yetersiz ve eksik olduğu sonucuna ulaşılmaktadır. Çalışmadan elde edilen sonuçlar doğrultusunda, Sakin Şehir Yalvaç'ın sürdürülebilir yerel kalkınma faaliyetlerine turizm ışı̆̆ında katkı sağlayabilecek şekilde aşağıdaki öneriler sunulabilir:

- Turizm açısından destinasyonun tanıtılması, el işi ürün satışını gerçekleştiren girişimcilerinin desteklenmesi, yapılan el işi ürünlerin bölgeyi tanıtıyor olması, yöresel yiyecekler ve kültürel değerlerin Yalvaç’ı yansıtıyor olması açısından yerine getirilmesi gerekli hususlardandir.

- $\quad$ Özellikle el işi ürün satışlarının en iyi şekilde tanıtılması ve desteklenmesi için kadın girişimcilerin desteklenmesi, yatırımcıların bu bölgeye katkısının artırılması gerekmektedir.

- Sakin Şehir hizmetlerinin belediyeler tarafından gerçekleştirilmesi aşamasında valilik, kaymakamlık, üniversite gibi kamu kurumlarının yanında özel sektör ve çeşitli yerel işletmelerin de katkısı en iyi şekilde sağlanmalıdır.

- $\quad$ Özellikle Sakin Şehir halkı olarak bölge halkının belediye hizmetlerinin sunulması aşamasında çaba sarf etmesi son derece önemlidir. Örneğin belediyelerin çöp ve atıkların ayrıştırılması, bölgedeki bina vb. yapısal görüntü kirliliklerinin önüne geçilmesi konusunda sunduğu hizmetlerin, yerel halk tarafindan destekleniyor olmasi gerekmektedir.

- $\quad$ Ayrica yerel festival ve etkinliklerin düzenlenmesi, ulusal ve uluslararasi anlamda tanıtımların gerçekleştirilmesi, yöresel ürün tanıtımlarının yapılması, yerel halkın katılımının gerekli olduğu noktalardır. Fakat yapılan görüşmelerden yerel halkın Sakin Şehir konusunda tam anlamıyla bilgilendirilmedikleri görülmektedir. Sakin Şehir hizmetlerinin daha iyi seviyede 
görülebilmesi için yerel halkın bu konuda çeşitli yöntemler ile desteklenmesi ve bilgi sahibi olmasına yönelik çalışmalar gerçekleştirilmelidir.

- Sakinlik kavramının tam anlamıyla uygulamaya geçebilmesi için öncelikle bölgede eksik kalan restorasyon çalışmalarının tamamlanması, hızlı yaşamın çeşitli sorunlarının (alışveriş merkezleri, fast food restoranları, göç ile gelen nüfus artışı, trafik yoğunluğu vb.) en aza indirilmesi sağlanmalıdır.

- Turistik altyapı ve üstyapı çalışmalarının arttırılmasına önem verilmelidir. Ziyaretçilerin ihtiyaçlarını giderebilecekleri, dinlenebilecekleri ve rahatlıkla alışveriş yapacakları mekanlar yapılmalıdır.

- Merkezde kaliteli ve nezih konaklama tesisinin bulunmayışı ziyaretçilerin konaklama yapmalarına engel olmaktadır. Bu doğrultuda konaklama tesislerine önem verilmelidir.

- Ziyaretçilerin Psidia Antik Kenti'nin dışında kalan yerleri de gezebilmeleri sağlanmalıdır. Bu kapsamda gezi güzergahları belirlenerek ziyaretçilere sunulmalıdır.

- Sakin Şehir Yalvaç'ın ulusal ve uluslararası çapta tanınırlığının sağlanması için reklam ve tanıtım faaliyetlerine ağırlık verilmelidir. Öncelikle yerel halk bilgilendirilmeli ve tanıtılmalıdır. Sakin Şehir ağının şehir imajına olan katkıları değerlendirilmelidir.

Yapılacak olan bu vb. tüm faaliyetlerin işbirliği çerçevesinde gerçekleştirilerek bölgenin ve ülkenin genel anlamda tanılırlık seviyesinin artırılması gerçekleştirilmiş, kalkınmaya hizmet edilmiş olunacaktır.

\section{Yazarların Katkı Oranı}

Bu makaleye birinci yazarın $\% 50$, ikinci yazarın $\% 50$ oranında katkısı vardır.

\section{Çıkar Çatışması}

Bu çalışmada çıkar çatışması teşkil edebilecek bir durum yoktur.

\section{Açıklama}

Bu makale, Süleyman Demirel Üniversitesi Sosyal Bilimler Enstitüsü tarafindan kabul edilen "Sakin Şehir Hizmetlerinin Sürdürülebilir Turizm Çerçevesinde Yerel Kalkinmaya Etkisinin İncelenmesi: Yalvaç Örneği” başlıklı yüksek lisans tezinden türetilmiştir.

\section{Kaynaklar}

Akman, E., Akman, Ç. ve Karakuş, M. (2018). Yavaş şehir kriterleri üzerinden Seferihisar belediyesinin faaliyetlerinden vatandaş memnuniyetinin analizi. Afyon Kocatepe Üniversitesi Sosyal Bilimler Dergisi, 20(2), 65-84.

Alagöz, M. (2018). Sürdürülebilir kent bağlamında cittaslow yaklaşımı: Eğirdir ilçesinin cittaslow kriterleri açısından incelenmesi. Asia Minor Studies, 6. Sempozyum Özel Sayısl, 138-149.

Aydın, E. E. ve Karakayacı, Z. (2021). Cittaslow modelinin kırsal alanın korunmasındaki rolü. Journal of International Social Research, 14(76).

Aziz, A. (2014). Sosyal bilimlerde araştırma yöntemleri ve teknikleri. Ankara, Nobel Yayınc1lık.

Bal, H. (2013). Nitel araştırma yöntemi. Isparta: Fakülte Kitabevi.

Ball, S. (2015). Slow cities. in theme cities: solutions for urban problems. Springer Dordrecht.

Baltacı, A. (2019). Nitel araştırma süreci: Nitel bir araştırma nasıl yapılır? Ahi Evran Üniversitesi Sosyal Bilimler Enstitüsü Dergisi, 5(2), 368-388. 
Baykal, F. ve Ataberk, E. (2020). Karşılaştırmalı bir araştırma: Kuramdan uygulamaya Türkiye'de cittaslow hareketi. Safran Kültür ve Turizm Araştırmaları Dergisi, 3(3), 290-316.

Bayyurt, Y. ve Seggie, F. N. (2017). Nitel araştırma yöntemi. F.N. Seggie ve Y. Bayyurt (Ed.). Nitel araştırma: yöntem, teknik, analiz ve yaklaşımları, Ankara: Anı Yayıncılık.

Berg, B. L. ve Luna, H. (2015). Nitel araştırmayı desenleme, H. Aydın (Ed.). Sosyal bilimlerde nitel araştırma yöntemleri içinde, Konya: Eğitim Yayınevi.

Bilgi, M. G. (2013). Türkiye'nin sakin şehirlerinde perma kültürel koruma, planlama, yönetim ve eğitim pratikleri. Selçuk Üniversitesi Sosyal Bilimler Enstitüsü Dergisi, (29), 45-59.

Cittaslow International Network, (2020). Cittaslow list October 2020, https://www.cittaslow.org/sites/default/files/content/page/files/246/cittaslow_list_october_202 0.pdf adresinden 25.11.2020 tarihinde erişilmiştir.

Cittaslow Türkiye, (2018). Üyelik süreci ve kriterler, http://cittaslowturkiye.org/uyelik-sureci-vekriterler/ adresinden 18.11.2018 tarihinde erişilmiştir.

Cittaslow Türkiye, (2020). http://cittaslowturkiye.org/\#turkiye adresinden 16.11.2020 tarihinde erişilmiş̧tir.

Çakar, D. (2016). Kültürel mirası koruma bağlamında" yavaş şehir"(cittaslow) hareketi: Türkiye örneği. Yüksek Lisans Tezi, Dokuz Eylül Üniversitesi, Fen Bilimleri Enstitüsü, İzmir.

Çolak, E. C. (2019). Sakin şehir Yalvaç'ın cittaslow uluslararası kriterleri kapsamında değerlendirmesi. Türkiye Mesleki ve Sosyal Bilimler Dergisi, (1), 89-107.

Ekinci, M. B. (2014). The cittaslow philosophy in the context of sustainable tourism development; the case of Turkey. Tourism Management, 41, 178-189.

Farelnik, E., and Stanowicka, A. (2016). Smart city, slow city and smart slow city as development models of modern cities, Olsztyn Economic Journal, 11(4), 359-370

Güler, A., Halıcıoğlu, M. B., ve Taşğın, A. (2015). Sosyal bilimlerde nitel araştırma: teorik çerçevepratik öneriler-7 farklı nitel araştırma yaklaşımı-kalite ve etik hususlar. Ankara: Seçkin Yayınc1lı.

Gürbüz, S., ve Şahin, F. (2017). Sosyal bilimlerde araştırma yöntemleri. Ankara: Seçkin Yayıncılık.

Jang, H. and Jung, T. (2015). Going slow and curvy: understanding the philosophy of the cittaslow slowcity phenomenon. Korea: Springer Publishing.

Knox, P. L. (2005). Creating ordinary places: slow cities in a fast world. Journal Of Urban Design, $10(1), 5-11$.

Kocaman, M. ve Kocaman, E. (2019). Yavaş şehir modelinde kültürel ve gastronomik ürünler ile marka şehir oluşturmak: Zile örneği, İstanbul Ticaret Üniversitesi Sosyal Bilimler Dergisi, $18(35), 837-850$.

Kozak, M. (2017). Bilimsel araştırma: tasarım, yazım ve teknikleri. 3. Basım, Ankara: Detay Yayınc1lik.

Kuş, E. (2009). Nicel-nitel araştırma teknikleri: sosyal bilimlerde araştırma teknikleri: nicel mi? nitel $m i$ ? Anı Yayıncilı. 
Küçük, M. ve Güneş, G. (2013). Yerel kalkınmada bir etken olarak turizm: Yerel sivil toplum kuruluşlarının görüşleri. Çağdaş Yerel Yönetimler, 22(4), 23- 50.

Mayer, H. and Knox, P. (2010). Small-town sustainability: Prospects in the second modernity. European Planning Studies, 18(10), 1545-1565.

Miele, M. (2008). Cittaslow: producing slowness against the fast life. Space And Polity, 12(1), 135156.

Özür, N. K. (2016). Sakin şehir/cittaslow hareketi ve yerleşme coğrafyası. Süleyman Demirel Üniversitesi Fen Edebiyat Fakültesi Sosyal Bilimler Dergisi, (37), 151-157.

Perano, M., Abbate, T., La Rocca, E. T. and Casali, G. L. (2019). Cittaslow \& fast-growing smes: evidence from europe, Land Use Policy, (82), 195-203.

Pink, S. (2008). Sense and sustainability: The case of the slow city movement. Local Environment, 13(2), 95-106.

Pink, S. (2009). Urban social movements and small places: Slow cities as sites of activism. City, 13(4), 451-465.

Seferihisar Belediyesi, (2019). http://seferihisar.bel.tr adresinden 16.01.2019 tarihinde erişilmiştir.

Sezgin, M. ve Ünüvar, Ş. (2011). Yavaş Şehir Sürdürülebilirlik ve Şehir Pazarlaması Ekseninde, Konya: Çizgi Kitabevi.

Sırım, V. (2012). Çevreyle bütünleşmiş bir yerel yönetim örneği olarak "sakin şehir" hareketi ve Türkiye’nin potansiyeli. Tarih Kültür ve Sanat Araştırmaları Dergisi, 1(4), 119-131.

Şahin, İ., ve Kutlu, S. Z. (2014). Cittaslow: sürdürülebilir kalkınma ekseninde bir değerlendirme. Journal of Tourism and Gastronomy Studies, 2(1), 55-63.

Tosun, E. K. (2013). Yaşam kalitesi ekseninde şekillenen alternatif bir kentsel yaşam modeli: Yavaş kentleşme hareketi, Uludağ Üniversitesi İktisadi ve İdari Bilimler Fakültesi Dergisi, 32(1), 215- 237.

Tunçer, M. ve Olgun, A. (2017). Seferihisar'ın ekonomik ve mali yapısı üzerinden sakin şehir uygulamalarına ilişkin bir inceleme. Uluslararası Ekonomi ve Yenilik Dergisi, 3(1), 47-72.

Tunçsiper, B. ve Yılmaz, G. Ö. (2009). Yerel ekonomik kalkınma sürecine turizm sektörünün etkisi. Dumlupınar Üniversitesi Sosyal Bilimler Dergisi, 24, 53-61.

Yalçın, A., Yalçın, S. ve Alııı, Ç. (2018). Sürdürülebilir bir yerel kalkınma modeli olarak cittaslow ağı ve kağızman'ın üyelik potansiyeli. Kafkas Üniversitesi, 1-21

Yıldırım, A. ve Şimşek H. (2016). Sosyal bilimlerde nitel araştırma yöntemleri. 11. Bask1, Ankara: Seçkin Yayıncılık. 


\section{Extended Abstract}

\section{Introduction}

The Cittaslow movement plays a leading role in the preservation of cities with minimal and distinctive features. The movement was founded in Italy in 1999 in the light of Paolo Saturnini's ideals. The Cittaslow movement was founded on 15 October 1999 in Orvieto, Italy by Paolo Saturnini (Mayer and Knox, 2010). The basic principles of the movement were established by Carlo Petrini, the founder of the Slow Food movement, and Paolo Saturnini, by adapting the principles of the Slow Food movement to urban life (Pink, 2009). While the movement initially covered only major cities in Italy, it spread around the world as part of the developing process and gained international importance. Contrary to its name, the movement has been spread and developed rapidly in the world (Tunçer \& Olgun, 2017). With the Cittaslow movement, it plays an active role in protecting the local characteristics of the cities as well as ensuring local development. The importance of the International Union of Cittaslow is increasing rapidly in Turkey day by day. Our country is home to 18 Cittaslow. Cittaslow membership also supports the increase of tourism revenues by promoting and advertising destinations. In this context, tourism activities are an important part of the Cittaslow movement in supporting local development. In this study, it is aimed to determine the impact of Cittaslow member Yalvaç district on local development through local stakeholders within the scope of tourism activities. For this purpose, semi-structured interviews were conducted with 15 participants residing in Yalvaç district. Participants were determined according to purposeful sampling and consist of members of the private sector, public sector and non-governmental organizations. As a result of the study, it was determined by the participants that the effect of Cittaslow activities of Yalvaç district on local development was not fully realized. The research covers local stakeholders living within the borders of Yalvaç district of Isparta. In order to determine the extent to which the Cittaslow movement, the local development model, benefits development, research data were presented to the study groups using qualitative methods. Within the scope of qualitative research, a semi-structured interview form was applied to public employees, private sector employees and non-governmental organization members. With the semi-structured interview, it was revealed the extent to which local stakeholders are involved in the Cittaslow process and contribute to development.

\section{Method}

The study was realised using the semi-structured interview technique, which is a qualitative research model. The study was carried out in Yalvaç / Isparta borders for local stakeholders operating in Yalvaç District of Isparta province. Participants were determined by purposeful sampling, one of the non-probabilistic sampling techniques. The target population of this study includes members of the Cittaslow Association, which has a presence in Turkey. However, since reaching all Cittaslow is difficult in terms of time, cost and space, the sample has been selected. The sample of the study was selected from Yalvaç district of Isparta, which became a member of the Cittaslow in 2012. The working group to be interviewed was determined in advance and the interviews were carried out by phone by requesting an appointment and by direct interview. In total, 15 participants were interviewed and 6 of these participants were public, 6 private sector employees and 3 non-governmental organization members. During the data collection process, interviews lasting an average of 15 minutes were conducted with each participant. While asking questions to the participants during the interview, their permission was obtained and the interview was recorded on a tape recorder. The audio recordings were turned into a written transcript on the day of the interview or the day after the interview at the latest. The total interview records consist of 17 Word pages. The data have been compiled under three main themes. Ethics committee approval was obtained for the study.

\section{Findings}

From the interviews with 15 participants in total, 6 participants consist of public sector employees, 6 participants from private sector employees and 3 participating NGO members. 
Participants consist of $40 \%$ public employees, $40 \%$ private sector employees and $20 \%$ NGO members. The study group consists of 11 men and 4 women. $73.3 \%$ of the participants consisted of male study group. In the light of the data obtained from the semi-structured interview form, evaluations were made on the basis of public sector, private sector and non-governmental organizations under three headings.

1. Plans as a Cittaslow and Tourism Purposes

2. Advantages of Yalvaç as a Cittaslow and Local Development Activities of the Cittaslow Association

3. Yalvaç's Cittaslow Criteria and Activities of the Local People

\section{Result, Discussion and Conclusion}

Despite the main problem of the rapidity of social life, the Union of Calm City promises to breathe and slow down. It offers to live in local cities that preserve their core values by escaping from the overwhelming traffic, noise, pollution and density of metropolitan cities. Especially with the recent Covid-19 process, it is interesting that Calm Cities respond to the criteria sought. As a result of the literature review in the selection of the study area, it was discovered that there were deficiencies and it was preferred to work within the concept of the Peaceful City union. The limited number of studies to measure the support provided by Calm City services to local development was effective in the selection of the study topic. Yalvaç became a member of the international Calm City association in 2012. Within the scope of the period from the membership process to the present, the knowledge of the district and its intensity in the fields of activity draw attention. In order to obtain this knowledge in its full sense, the data collection process was made through the qualitative method in the research. Within the scope of qualitative research, data were collected by face to face semi-structured interview method with 15 participants. These participants were selected according to the purposeful sampling method and selected from among public sector employees, private sector employees and nongovernmental organizations in order to ensure that the findings are homogeneous and representative. According to the results of the research, it is concluded that Yalvaç district has an advantage in increasing its recognition by mentioning its name internationally as a member of the Calm City and that the city is advertised thanks to membership. In addition, it has been concluded that living standards are raised with membership, healthy food is produced and consumed, infrastructure and superstructure facilities are standardized, life-facilitating activities are carried out for people with disabilities and it contributes to the construction of bicycle paths for clean nature. Yalvaç district stands out with its cultural and historical values. It is revealed that the majority of visitors come in line with religious tourism and that historical places need to be restored quickly. In the light of the research results, the suggestions are that local organizations and local people should act together in order to ensure local development. In addition, attention should be paid to improving efforts over the existing tourism potential of Yalvaç district. These studies should be done to increase the number of accommodation facilities, to organize events for tourists and to place souvenir sales in accessible places. 